\title{
Termocronologia por traços de fissão em apatita em rochas ígneas do embasamen- to e sedimentar da Bacia do Amazonas, na região de Itaituba, PA, Brasil
}

\author{
Aline Carla Miranda de PINA ${ }^{1}$, Candido Augusto Veloso MOURA ${ }^{1} \&$ Maria Lidia VIGNOL-LELARGE ${ }^{2}$
}

1. Centro de Geociências, Departamento de Geoquímica e Petrologia, Universidade Federal do Pará. Rua Augusto Corrêa, $\mathrm{n}^{\circ} 1$, Gua- $^{-}$ má66075-900, Belém, PA, Brasil. Caixa-Postal 8608. E-mail: alinepina2003@yahoo.com.br, candido@ufpa.br.

2. Laboratório de Geologia Isotópica, Instituto de Geociências, Universidade Federal do Rio Grande do Sul. Av. Bento Gonçalves, 9500, CEP: 91501-970, Porto Alegre, RS, Brasil. E-mail: lidia.vignol@ufrgs.br.

Recebido em 04/2012. Aceito para publicação em 03/2014.

Versão online publicada em 15/05/2014 (www.pesquisasemgeociencias.ufrgs.br)

\begin{abstract}
Resumo - Com o intuito de contribuir para o entendimento da história termotectônica da borda sul da Bacia do Amazonas, foi aplicado o método Traços de Fissão em Apatita (TFA) em rochas ígneas paleoproterozoicas $(\sim 1,88 \mathrm{Ga})$, pertencentes ao embasamento, situadas na região de Itaituba (PA), bem como em uma amostra do arenito da sequência Pensilvaniano-Permiana. As idades TFA obtidas e a modelagem dos dados TFA revelaram para as rochas do embasamento, a existência de dois episódios de resfriamento separados por um período de aquecimento.0 episódio de resfriamento mais antigo ocorrido na faixa de 280306 Ma pode revelar a exumação relacionada à aglutinação do Pangéia (320-270 Ma) e a deglaciação do Gondwana ( $\sim 300 \mathrm{Ma})$. 0 segundo evento de resfriamento (117-98 Ma) pode estar relacionado à exumação decorrente da reconhecida deformação das rochas da porção sudoeste da Bacia do Amazonas durante o Eocretáceo. A etapa intermediária de aquecimento pode estar relacionada ao magmatismo Penatecaua ( $\sim 200 \mathrm{Ma}$ ) registrado na bacia, e associado à ruptura do Pangéia e formação do Atlântico Central. A rocha sedimentar da Bacia do Amazonas registrou o evento de soerguimento do Eocretáceo e revelou ainda a aceleração desse soerguimento/exumação a partir do início do Paleógeno.

Palavras chave: termocronologia, traços de fissão, magmatismo, soerguimento, exumação, Bacia do Amazonas
\end{abstract}

\begin{abstract}
APATITE FISSION TRACK THERMOCHRONOLOGY APPLIED TO IGNEOUS BASEMENT AND SEDIMENTARY ROCKS FROM AMAZONAS BASIN, IN ITAITUBA REGION PA, BRAZIL.The apatite fission track thermochronology was used to investigate the thermotectonic evolution of the Amazonas Basin in the region of Itaituba (PA). The apatite fission track (AFT) data are mainly from the Paleoproterozoic igneous rocks of the basement ( $1.88 \mathrm{Ga})$, as well as a sample of the sandstone sequence Pennsylvanian-Permian. The fission track ages and mathematical modeling data of the basement samples suggested two cooling/uplift events and a heating event between them. The older cooling/uplift event, starting between 306 and $280 \mathrm{Ma}$, may be associated with the Pangea amalgamation (320-270 Ma) and with the deglaciation of Gondwana ( $300 \mathrm{Ma})$. The second cooling/uplift event, which started between 117 and 98 Ma may be related to the deformation (anticlines and inverse faults) in the rocks of the Amazonas Basin that occurred during the Upper Cretaceous. The heating event that occurred in between is associated with the widespread mafic magmatism related to break up of Pangea ( $\sim 200 \mathrm{Ma}$ ) and formation of the Central Atlantic Ocean, known as Penatecaua magmatism in the Amazonas Basin. The ATF data for the sedimentary rock of the basin recorded the Upper Cretaceous uplift event and suggested a higher rate of exhumation in the beginning of the Paleogene.

Key words: thermochronology, fission tracks, magmatism, uplift, exhumation, Amazonas Basin
\end{abstract}

\section{Introdução}

A Bacia do Amazonas, juntamente com as bacias do Solimões, Parnaíba e Paraná, faz parte do conjunto de bacias do Paleozoico que cobre boa parte do território brasileiro. Há vários anos, os sistemas petrolíferos dessas bacias têm sido estudados visando à exploração de óleo e gás, no entanto, apenas na Bacia do Solimões está sendo produzido petróleo em escala comercial. Na Bacia do Amazonas, por sua vez, existem fortes indicações da geração de petróleo, pois ocorrem rochas geradoras no Siluriano e no Devoniano (Cunha et al., 1994). No entanto, os diferentes episódios de subsidência e soerguimento identificados ao longo do Paleozoico (Cunha et al., 2007) e eventos tectônicos posteriores ocorridos no Jurássico Inferior (Zalán, 2004), Cretáceo Inferior e Paleógeno (Campos \& Teixeira, 1988), sugerem uma complexa evolução tectonotermal para a Bacia do Amazonas. 0 entendimento dessa história termotectônica é fundamental para a elaboração de modelos mais acurados de geração, (re)migração e trapeamento de petróleo nessa bacia. Tais informações 
podem ser interpretadas com o auxílio da termocronologia por traços de fissão em apatita.

A termocronologia pelo método dos Traços de Fissão em Apatita (TFA) é baseada nos danos de irradiação resultantes da fissão espontânea do ${ }^{238} \mathrm{U}$, e é reconhecida como uma ferramenta que permite reconstruir a história térmica e tectônica da crosta superior terrestre (3-5 km), ao longo dos últimos milhões de anos, segundo os trabalhos reunidos por Kohn \& Green (2002).

A variação das idades traços de fissão e a distribuição dos comprimentos dos traços confinados são primeiramente controladas pelo resfriamento das rochas no interior da crosta, que pode ter iniciado por movimentos da crosta e consequente denudação da superfície terrestre e/ou mudanças no regime térmico. Segundo Green et al. (1986), para retenção de traços de fissão em apatitas admite-se um intervalo entre $75^{\circ}$ e $125^{\circ} \mathrm{C}$, para uma taxa de resfriamento de entre $1-10^{\circ} \mathrm{C} / \mathrm{Km}$. Esta variação está relacionada à composição da apatita e ao tempo de duração do evento térmico entre $\left(10^{6}-10^{8} \mathrm{Ma}\right)$. Através de procedimentos de modelagem numérica inversa esses parâmetros podem estar de acordo com rotas tempo-temperatura que permitem mapear processos térmicos e tectônicos com bastante detalhe (Khon \& Green, 2002).

0 único estudo termocronológico publicado na Bacia do Amazonas foi realizado nos diques de diabásio de 200 Ma que ocorrem na região de Monte Alegre (Negrão, 2011). Este estudo registrou idades TFA entre 53,2 e 43,6 Ma, que marcam um importante evento tectônico do Paleógeno. Com o intuito de contribuir para o entendimento da história termotectônica da borda sul da Bacia do Amazonas, neste trabalho, o método TFA foi aplicado em rochas ígneas paleoproterozoicas $(\sim 1,88$ Ga), pertencentes ao embasamento dessa bacia, situadas na região de Itaituba, Estado do Pará. Esta técnica foi também empregada em uma amostra de arenito da sequência Pensilvaniano-Permiana da bacia (Cunha et al., 2007).

\section{Contexto geológico regional}

O substrato sobre o qual se instalou a Bacia do Amazonas foi formado gradativamente desde o Arqueano até o Paleoproterozoico, e está representado por rochas pertencentes às províncias geocronológicas Amazônia Central, Ventuari-Tapajós e Maroni-Itacaiunas, propostas por Tassinari \& Macambira (1999).

$\mathrm{Na}$ área de estudo, o embasamento da Bacia do Amazonas pertence à província geocronológica Amazônia Central, que é constituída por rochas com idades modelo Sm-Nd mais antigas que 2,3 Ga. Nesta Província foram reconhecidos dois domínios principais denominados de blocos Carajás e Xingu-Iricoumé (Tassinari \& Macambira, 2004) (Fig. 1A).

No bloco Xingu-Iricoumé dominam rochas vulcânicas félsicas a intermediárias e granitóides cálcio-alcalinos intrudidos por granitos alcalinos a sub-al- calinos tipo A, paleoproterozóicos $(1,88-1,9 \mathrm{Ga})$ não metamorfizados.

Na região de Itaituba, situada no setor Xingu deste bloco, as rochas vulcânicas recebem o nome de Grupo Iriri que é constituído por riolitos, enquanto os granitóides cálcio-alcalinos são denominados de Suíte Intrusiva Maloquinha compostos por sienogranitos e Suíte Intrusiva Parauari formada por monzogranitos porfiríticos. Nesta região também ocorrem rochas gabróicas cálcio-alcalinas de Alto K, denominadas de Suíte Intrusiva Igarana (CPRM, 2009).

No final do ciclo Brasiliano ( $\sim 500 \mathrm{Ma})$ foram depositados no Cráton Amazônico os sedimentos siliciclásticos reunidos nas formações Prosperança e Acari (Grupo Purus) que são precursores dos episódios anteriores que levaram a instalação da Bacia do Amazonas (Cunha et al., 2007).

A evolução estratigráfica da Bacia do Amazonas envolve a ocorrência de diversos ciclos de sedimentação a partir do Ordoviciano. 0 entendimento dessa evolução tem sido aperfeiçoado com o avanço dos estudos geológicos (Caputo et al., 1971; Cunha et al., 1994), e a proposta estratigráfica de Cunha et al. (2007) foi adotada neste trabalho.

0 registro estratigráfico da sinéclise do Amazonas inicia-se com a Sequência Ordovício-Devoniana que é caracterizada por alternâncias de sucessões glaciais e marinhas, com ingressões marinhas de leste para oeste em onlap sobre o Arco de Purus, que impedia a conexão entre as bacias do Amazonas e do Solimões. Após a discordância relacionada à Orogenia Caledoniana iniciou-se um ciclo sedimentar, de natureza transgressivo-regressiva, que depositou a Sequência Devono-Tournaisiana. A intensa atividade tectônica que ocorreu nas margens da placa Sul-Americana devido à Orogenia Acadiana resultou no soerguimento e erosão desta sequência. Sobre esta superfície erosiva depositaram-se os arenitos e pelitos fluvio-deltaicos e litorâneos da Sequência Neoviseana. Em consequência da Orogenia Herciniana, que levou a formação do Supercontinente Pangéia, o topo da Sequência Neoviseana, foi submetido a extenso processo erosivo. Após um hiato temporal de $15 \mathrm{Ma}$, instalou-se um novo ciclo transgressivo-regressivo, durante o Neocarbonífero, acompanhado de mudança de clima frio para quente e árido, que depositou os arenitos, carbonatos e evaporitos da Sequência Pensilvaniano-Permiana (Cunha et al., 2007).

A fragmentação do Pangéia no Neotriássico propiciou a ascensão de magma basáltico que deu origem a um enxame de diques e soleiras de diabásio, que atravessam as sequências paleozoicas da Bacia do Amazonas. Datações pelo método Ar-Ar indicaram que a idade desse magmatismo máfico situa-se entre 191 e $210 \mathrm{Ma}$ (Zalán, 2004).

A abertura do Atlântico Equatorial a leste, e a zona de subducção andina cretácea, a oeste da placa Sul-Americana resultaram em esforços compressivos 
ENE-WSW e WNW-ESE, que provocaram reativações de fraturas e deformação compressiva no continente (Campos \& Teixeira, 1988). Este episódio é a mais expressiva deformação que afetou a Plataforma Sul-Americana durante a reativação Wealdeniana e é denominado de Diastrofismo Juruá (Almeida, 1972).

Ao final dos esforços compressivos relacionados ao Diastrofismo Juruá, ocorreu um relaxamento tectônico iniciando-se um novo ciclo deposicional denomi- nado Mega Sequência Mesozoico-Cenozoica constituídas pelas Sequências Cretácea e Paleógena, que reúne os sedimentos clásticos continentais das formações Alter do Chão e Solimões, incluídas no Grupo Javari (Cunha et al., 1994; Eiras et al., 1994). Esta unidade se assenta diretamente sobre a discordância do topo do Paleozoico (discordância pré-cretácea).

As unidades datadas neste trabalho podem ser visualizadas na figura $1 \mathrm{~B}$ e nas tabelas 1 e 2 .
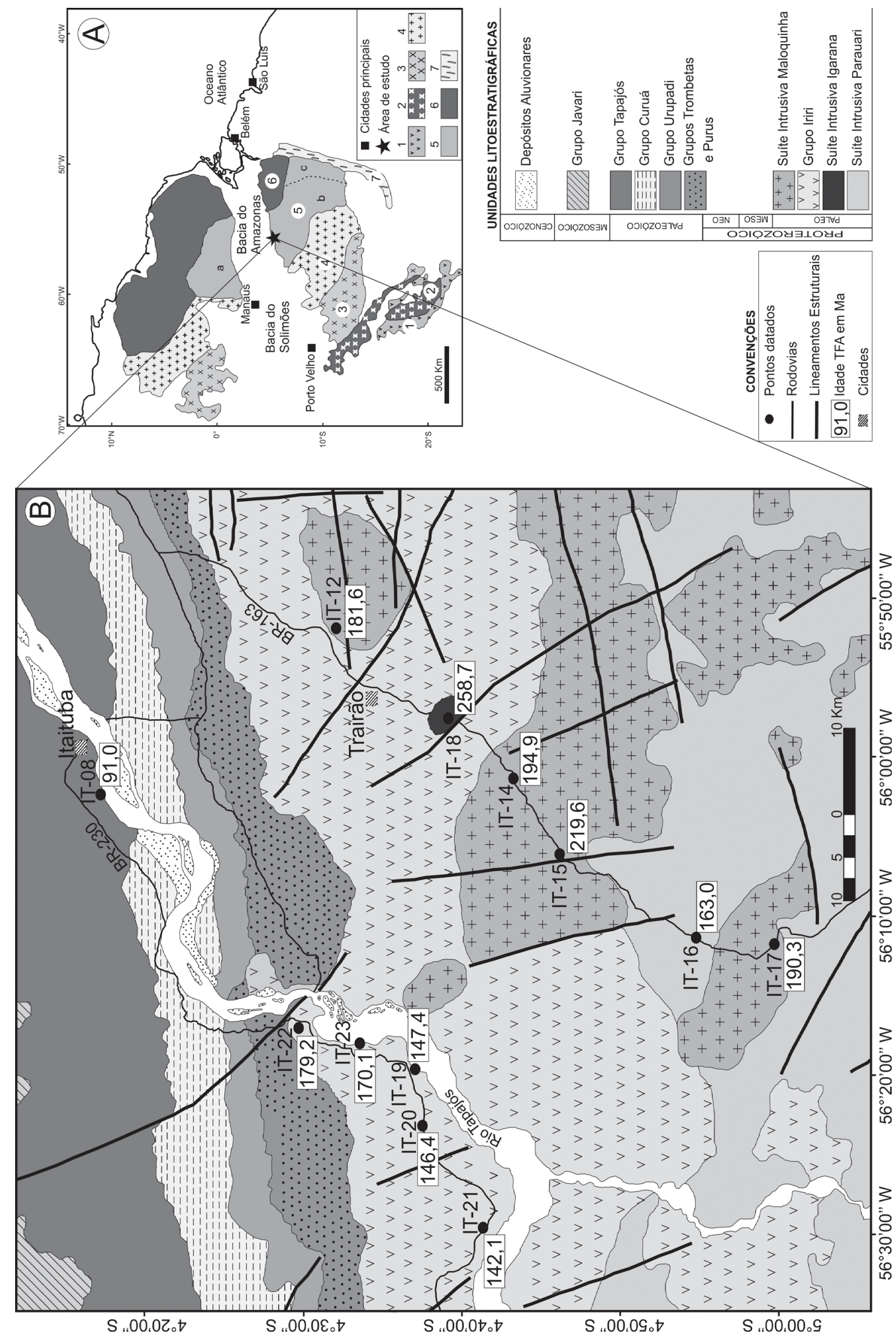

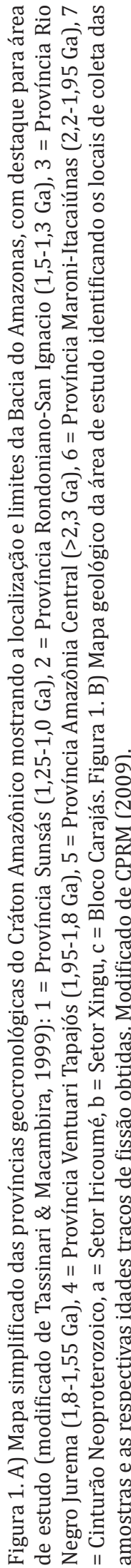


Tabela 1. Amostras datadas pelo MTFA, destacando as idades das unidades trabalhadas e seus respectivos autores: (a) Playford \& Dino (2000), (b) Vasquez et al. (1999), (c) Santos et al. (2000), (d) Santos et al. (2000), (e) Moura et al. (1999).

\begin{tabular}{|c|c|c|c|c|c|c|}
\hline \multirow{2}{*}{$\begin{array}{c}\text { Identificação } \\
\text { da amostra } \\
\text { coletada }\end{array}$} & \multicolumn{2}{|c|}{$\begin{array}{l}\text { Localização da amostra } \\
\text { (coordenadas geográficas) }\end{array}$} & \multirow{2}{*}{$\begin{array}{l}\text { Unidade } \\
\text { amostrada }\end{array}$} & \multirow{2}{*}{ Idade (Ma) } & \multirow{2}{*}{ Litologia } & \multirow{2}{*}{ Mineralogia } \\
\hline & Latitude & Longitude & & & & \\
\hline IT-08 & $4^{\circ} 17^{\prime} 25^{\prime \prime} \mathrm{S}$ & $56^{\circ} 02^{\prime} 20^{\prime \prime} \mathrm{W}$ & $\begin{array}{l}\text { Formação } \\
\text { Monte Alegre }\end{array}$ & 318-316 (a) & Arenito & $\begin{array}{l}\text { Quartzo, K-feldspato, plagioclásio, zircão, apatita } \\
\text { e rutilo }\end{array}$ \\
\hline IT-12 & $4^{\circ} 32^{\prime} 12^{\prime \prime} \mathrm{S}$ & $55^{\circ} 53^{\prime} 52^{\prime \prime} \mathrm{W}$ & $\begin{array}{l}\text { Suíte Intrusiva } \\
\text { Maloquinha }\end{array}$ & 1883 (b) & Granito & $\begin{array}{c}\text { Ortoclásio, quartzo, plagioclásio, zircão, opacos, } \\
\text { apatita, e allanita }\end{array}$ \\
\hline IT-14 & $4^{\circ} 43^{\prime} 18^{\prime \prime} \mathrm{S}$ & $56^{\circ} 01^{\prime} 31^{\prime \prime} \mathrm{W}$ & $\begin{array}{l}\text { Suíte Intrusiva } \\
\text { Maloquinha }\end{array}$ & 1883 (b) & Granito & $\begin{array}{c}\text { Ortoclásio, quartzo, plagioclásio, zircão, opacos, } \\
\text { apatita, e allanita }\end{array}$ \\
\hline IT-15 & $4^{\circ} 46^{\prime} 13^{\prime \prime} \mathrm{S}$ & $56^{\circ} 06^{\prime} 15^{\prime \prime} \mathrm{W}$ & $\begin{array}{l}\text { Suíte Intrusiva } \\
\text { Maloquinha }\end{array}$ & 1883 (b) & Granito & $\begin{array}{c}\text { Ortoclásio, quartzo, plagioclásio, zircão, opacos, } \\
\text { apatita, e allanita }\end{array}$ \\
\hline IT-16 & $4^{\circ} 54^{\prime} 48^{\prime \prime} \mathrm{S}$ & $56^{\circ} 11^{\prime} 31^{\prime \prime} \mathrm{W}$ & $\begin{array}{l}\text { Suíte Intrusiva } \\
\text { Parauari }\end{array}$ & 1891 (c) & Granito & $\begin{array}{l}\text { Feldspato, quartzo, plagioclásio, hornblenda, } \\
\text { biotita, clorita, zircão, apatita e opacos }\end{array}$ \\
\hline IT-17 & $4^{\circ} 59^{\prime} 48^{\prime \prime} \mathrm{S}$ & $56^{\circ} 11^{\prime} 37^{\prime \prime} \mathrm{W}$ & $\begin{array}{l}\text { Suíte Intrusiva } \\
\text { Maloquinha }\end{array}$ & 1883 (b) & Granito & $\begin{array}{c}\text { Ortoclásio, quartzo, plagioclásio, zircão, opacos, } \\
\text { apatita e allanita }\end{array}$ \\
\hline IT-18 & $4^{\circ} 39^{\prime} 41^{\prime \prime} \mathrm{S}$ & $55^{\circ} 57^{\prime} 37^{\prime \prime} \mathrm{W}$ & $\begin{array}{l}\text { Suíte Intrusiva } \\
\text { Igarana }\end{array}$ & 1880 (d) & Gabro & $\begin{array}{l}\text { Plagioclásio, olivina, piroxênio, opacos, zircão e } \\
\text { apatita }\end{array}$ \\
\hline IT-19 & $4^{\circ} 37^{\prime} 00^{\prime \prime} \mathrm{S}$ & $56^{\circ} 19^{\prime} 36^{\prime \prime} \mathrm{W}$ & Grupo Iriri & $1890(\mathrm{e})$ & Riolito & $\begin{array}{l}\text { Álcali-feldspato, plagioclásio, quartzo, opacos, } \\
\text { zircão e apatita }\end{array}$ \\
\hline IT-20 & $4^{\circ} 37^{\prime} 31^{\prime \prime S}$ & $56^{\circ} 23^{\prime} 19^{\prime \prime} \mathrm{W}$ & Grupo Iriri & $1890(\mathrm{e})$ & Riolito & $\begin{array}{l}\text { Álcali-feldspato, plagioclásio, quartzo, opacos, } \\
\text { zircão e apatita }\end{array}$ \\
\hline IT-21 & $4^{\circ} 41^{\prime} 24^{\prime \prime} \mathrm{S}$ & $56^{\circ} 29^{\prime} 39^{\prime \prime} \mathrm{W}$ & Grupo Iriri & $1890(\mathrm{e})$ & Riolito & $\begin{array}{l}\text { Álcali-feldspato, plagioclásio, quartzo, opacos, } \\
\text { zircão e apatita }\end{array}$ \\
\hline IT-22 & $4^{\circ} 28^{\prime} 14^{\prime \prime S}$ & $56^{\circ} 17^{\prime} 04^{\prime} \mathrm{W}$ & Grupo Iriri & $1890(\mathrm{e})$ & Riolito & $\begin{array}{l}\text { Álcali-feldspato, plagioclásio, quartzo, opacos, } \\
\text { zircão e apatita }\end{array}$ \\
\hline IT-23 & $4^{\circ} 33^{\prime} 20^{\prime \prime} \mathrm{S}$ & $56^{\circ} 17^{\prime} 57^{\prime \prime} \mathrm{W}$ & Grupo Iriri & $1890(\mathrm{e})$ & Riolito & $\begin{array}{l}\text { Álcali-feldspato, plagioclásio, quartzo, opacos, } \\
\text { zircão e apatita. }\end{array}$ \\
\hline
\end{tabular}

Tabela 2. Dados analíticos traços de fissão das amostras da região Itaituba, Pará.

\begin{tabular}{|c|c|c|c|c|c|c|c|c|c|c|c|}
\hline Amostra & $\begin{array}{l}\text { Altitude } \\
\text { (m) }\end{array}$ & $\mathrm{n}$ & $\begin{array}{c}\rho_{\varepsilon}(x 10 E+5) \\
\left(N_{e}\right)\end{array}$ & $\begin{array}{c}\rho_{\mathrm{i}}(\mathrm{x} 10 \mathrm{E}+5) \\
\left(\mathrm{N}_{\mathrm{i}}\right)\end{array}$ & $\begin{array}{c}\text { Rhod } 1 \text { e Rhod2 } \\
\left(10 \mathrm{E}+5 \mathrm{tr} / \mathrm{cm}^{2}\right) \\
(\mathrm{Nd})\end{array}$ & $\begin{array}{c}\text { Teor U } \\
(\%)\end{array}$ & $\begin{array}{l}\text { Disp.Idade } \\
\text { (D) (\%) }\end{array}$ & $\begin{array}{c}\mathrm{P}\left(\mathrm{X}^{2}\right) \\
(\%)\end{array}$ & $\begin{array}{l}\text { Idade } \\
\mathrm{TF} \pm \text { sd } \\
(\mathrm{Ma})\end{array}$ & $\begin{array}{c}\mathrm{Lc} \pm \sigma(\mu \mathrm{m}) \\
{[\mathrm{Nt}]}\end{array}$ & $\begin{array}{c}\text { Desvio- } \\
\text { padrão } \\
(\mu \mathrm{m})\end{array}$ \\
\hline IT-08 & 00 & 30 & $\begin{array}{c}5,77 \\
(388)\end{array}$ & $\begin{array}{c}4,42 \\
(297)\end{array}$ & $\begin{array}{c}3,803 \\
(7987)\end{array}$ & 1.68 & 0,26 & 11,34 & $\begin{array}{c}91,0 \pm 10,9 \\
{[38-334]}\end{array}$ & $\begin{array}{c}11,65 \pm \\
0,47 \\
{[16]}\end{array}$ & 1,89 \\
\hline IT-12 & 64 & 64 & $\begin{array}{c}4,76 \\
(731)\end{array}$ & $\begin{array}{c}1,77 \\
(272)\end{array}$ & $\begin{array}{c}3,803 \\
(7987)\end{array}$ & 0.53 & 00 & 100 & $\begin{array}{c}181.6 \pm \\
18,8 \\
{[95-301]}\end{array}$ & $\begin{array}{c}9,87 \pm 0,49 \\
{[12]}\end{array}$ & 1,70 \\
\hline IT-14 & 184 & 56 & $\begin{array}{c}5,10 \\
(540)\end{array}$ & $\begin{array}{l}1,76 \\
(187)\end{array}$ & $\begin{array}{c}3,803 \\
(7987)\end{array}$ & 0.55 & 00 & 100 & $\begin{array}{c}194,9 \pm \\
22,1 \\
{[102-526]}\end{array}$ & $\begin{array}{c}12 \pm 1,09 \\
{[6]}\end{array}$ & 2,68 \\
\hline IT-15 & 128 & 40 & $\begin{array}{c}4,18 \\
(423)\end{array}$ & $\begin{array}{c}1,22 \\
(125)\end{array}$ & $\begin{array}{c}3,638 \\
(15280)\end{array}$ & 0.40 & 00 & 99.96 & $\begin{array}{c}219,6 \pm \\
27.7 \\
{[65-412]}\end{array}$ & $\begin{array}{c}11,94 \pm \\
0,56 \\
{[9]}\end{array}$ & 1,70 \\
\hline IT-16 & 77 & 68 & $\begin{array}{c}3,12 \\
(546)\end{array}$ & $\begin{array}{c}1,25 \\
(219)\end{array}$ & $\begin{array}{c}3,638 \\
(15280)\end{array}$ & 0.39 & 00 & 99,99 & $\begin{array}{c}163,0 \pm \\
16,6 \\
{[49-504]}\end{array}$ & $\begin{array}{c}10 \pm 0,53 \\
{[18]}\end{array}$ & 2,24 \\
\hline IT-17 & 182 & 30 & $\begin{array}{c}3,87 \\
(221)\end{array}$ & $\begin{array}{l}1,31 \\
(75)\end{array}$ & $\begin{array}{c}3,638 \\
(15280)\end{array}$ & 0.45 & 00 & 99.99 & $\begin{array}{c}190.3 \pm 29.1 \\
{[86-402]}\end{array}$ & $\begin{array}{c}11,46 \pm \\
0,64 \\
{[15]}\end{array}$ & 2,50 \\
\hline IT-18 & 61 & 36 & $\begin{array}{c}4,67 \\
(443)\end{array}$ & $\begin{array}{c}1,16 \\
(110)\end{array}$ & $\begin{array}{c}3,638 \\
(15280)\end{array}$ & 0.37 & 00 & 99.99 & $\begin{array}{c}258,7 \pm \\
33.7 \\
{[108-564]}\end{array}$ & $\begin{array}{c}12,85 \pm \\
0,39 \\
{[17]}\end{array}$ & 1,64 \\
\hline IT-19 & 25 & 57 & $\begin{array}{c}4,44 \\
(364)\end{array}$ & $\begin{array}{l}1,95 \\
(160)\end{array}$ & $\begin{array}{c}3,638 \\
(15280)\end{array}$ & 0.62 & 00 & 100 & $\begin{array}{c}147,4 \pm \\
18,8 \\
{[65-319]}\end{array}$ & $\begin{array}{c}12,14 \pm \\
0,91 \\
{[7]}\end{array}$ & 2,41 \\
\hline IT-20 & 60 & 74 & $\begin{array}{c}3,08 \\
(415)\end{array}$ & $\begin{array}{c}1,42 \\
(192)\end{array}$ & $\begin{array}{c}3,803 \\
(7987)\end{array}$ & 0.47 & 00 & 100 & $\begin{array}{c}146,4 \pm \\
16,9 \\
{[45-494]}\end{array}$ & $\begin{array}{c}11,83 \pm \\
0,65 \\
{[6]}\end{array}$ & 1,60 \\
\hline IT- 21 & 59 & 31 & $\begin{array}{c}3,19 \\
(260)\end{array}$ & $\begin{array}{c}1,52 \\
(124)\end{array}$ & $\begin{array}{c}3,803 \\
(7987)\end{array}$ & 0.48 & 00 & 99.92 & $\begin{array}{c}142,1 \pm 18,8 \\
{[45-398]}\end{array}$ & $\begin{array}{c}11,5 \pm 1,26 \\
{[8]}\end{array}$ & 3,58 \\
\hline IT-22 & 52 & 66 & $\begin{array}{c}7,03 \\
(525)\end{array}$ & $\begin{array}{c}2,56 \\
(191)\end{array}$ & $\begin{array}{c}3,638 \\
(15280)\end{array}$ & 0.82 & 00 & 100 & $\begin{array}{c}177,5 \pm \\
20,0 \\
{[78-350]}\end{array}$ & $\begin{array}{l}14,40 \pm \\
0,35 \\
{[20]}\end{array}$ & 1,59 \\
\hline IT-23 & 25 & 13 & $\begin{array}{c}8,77 \\
(372)\end{array}$ & $\begin{array}{c}3,27 \\
(139)\end{array}$ & $\begin{array}{c}3,638 \\
(15280)\end{array}$ & 1.07 & 00 & 98.35 & $\begin{array}{c}170,1 \pm \\
17,4 \\
{[111-283]}\end{array}$ & $\begin{array}{c}11,1 \pm 0,38 \\
{[20]}\end{array}$ & 1,51 \\
\hline
\end{tabular}

$\mathrm{n}$ = número de cristais de apatita datados; $\rho_{\mathrm{e}}=$ densidade de traços espontâneos; $\mathrm{Ne}=$ número total de traços espontâneos; $\rho_{\mathrm{i}}=$ densidade de traços induzidos; $\mathrm{Ni}$ = número total de traços induzidos determinados na amostra; Rhod1 e Rhod2=densidade traços induzidos do dosímetro CN5 relativos a pilha1 e pilha2 de irradiação; $\mathrm{Nd}=$ número total de traços induzidos contados no dosímetro CN5; Zeta= 360,38 26,27 para Aline Pina; em itálico as idades mínimas e máximas obtidas para cada amostra; Lc= média dos comprimentos dos traços confinados; $\sigma=$ erro associado; $\mathrm{Nt}=$ número de traços confinados medidos para cada amostra. Área de contagem do dosímetro $=10.000 \mu \mathrm{m}^{2}$, área de contagem elementar das amostras (área de 1 quadrado) $=100 \mu \mathrm{m}^{2}$. 


\section{Materiais e métodos}

Para o estudo de TFA foram coletadas 11 amostras de rochas ígneas $(\sim 1,88 \mathrm{Ga})$ do embasamento da Bacia do Amazonas e uma amostra de arenito da Formação Monte Alegre (unidade do Pensilvaniano da Bacia do Amazonas). As amostras do embasamento foram coletadas em duas seções ao longo das rodovias federais BR-163 e BR-230 situadas, respectivamente, a leste e oeste do rio Tapajós (Fig. 1B). A amostra de rocha sedimentar foi coletada nas margens desse rio.

As análises de traços de fissão foram realizadas no Laboratório de Geologia Isotópica da Universidade Federal do Pará (UFPA) e no Laboratório de Geologia Isotópica da Universidade Federal do Rio Grande do Sul (UFRGS).

As amostras foram trituradas, pulverizadas e peneiradas nas frações entre 180-125 $\mu \mathrm{m}$ e 125-75 $\mu \mathrm{m}$, seguida da separação magnética e por liquido denso (bromofórmio), e posterior triagem dos cristais de apatita em lupa. Após a montagem em resina epóxi e polimento dos cristais de apatita, estes-foram submetidos ao ataque químico com solução $5 \mathrm{M}$ de $\mathrm{HNO}_{3}$, sob temperatura de $20^{\circ} \mathrm{C}$ por um tempo médio de $25 \mathrm{~s}$. As amostras foram recobertas por um detetor externo (kapton) e, finalmente, irradiadas juntamente com vidros dosímetros CN5. Esses vidros dosímetros colocados entre as amostras foram utilizados para monitorar os gradientes de fluxo durante as irradiações. A irradiação foi realizada no reator nuclear do Instituto de Pesquisas Nucleares da Universidade de São Paulo (USP) e da Comissão Nacional de Energia Nuclear (CNEN). Visando um maior controle das condições de irradiação das amostras e uma calibração adequada da dosimetria neutrônica foram inseridos 3 dosímetros CN5 e 2 padrões naturais de Durango, ao longo dos $3 \mathrm{~cm} \mathrm{da}$ pilha de irradiação. 0 número total de traços de fissão induzidos $\mathrm{Nd}$ contados nos detetores CN5 foi de 21.267 e a média das densidades de traços de fissão induzidos Rhod se estabeleceu em 3,719 $\pm 0,02(10 \mathrm{E}+5 \mathrm{tr} /$ $\mathrm{cm}^{2}$ ). Considerando um desvio-padrão de $2 \sigma$, para essa dosimetria, constatou-se que não hávariação do fluxo neutrônico na posição de irradiação utilizada.

Ao retornar da irradiação, os detetores externos (kaptons) foram atacados quimicamente para a revelação dos traços de fissão induzidos, com uma solução em ebulição de $\mathrm{NaOCl}(14 \%)+\mathrm{NaCl}(12 \%)$ durante 8 min, e em seguida neutralizados com água destilada. Cada amostra foi montada em lâmina de vidro ao lado de seu detector externo correspondente. A contagem e medição dos traços foram feitas utilizando um microscópio biológico Zeiss Axioskop 40, com oculares de aumento 10x e objetiva de 100x, a seco. As medidas de comprimento dos traços confinados foram feitas com o auxílio de uma régua acoplada à ocular, que na objetiva de 100x possui menor divisão de $1 \mu \mathrm{m}$. Em princípio é necessário datar pelo menos 30 grãos e serem medidos em torno de 100 traços confinados por amostra, para obter um dado de traço de fissão robusto.

As idades TFA foram calculadas utilizando o programa TRACKKEY de Dunkl (2002). Todas as idades dos grãos individuais foram determinadas a partir da equação de Hurford \& Green (1983), com um erro de $\pm 2 \sigma$. Com o objetivo de uniformizar os cálculos entre a amostra sedimentar e as amostras do embasamento foi adotado o cálculo das idades centrais, proposto por Galbraith \& Laslett (1993). As idades centrais e idades médias ponderadas são idênticas quando as amostras passam no teste de $\chi^{2}$.Todas as amostras aqui datadas passaram no teste de $\chi^{2}$ o que indica, estatisticamente, que para cada uma delas, os grãos individuais pertencem a uma única população.

As histórias térmicas de todas as amostras foram determinadas por modelagem a partir do programa MonteTrax (Gallagher et al., 1993). Este programa associa simulações probabilísticas Monte Carlo e um algoritmo genético no qual são efetuadas interações das diferentes histórias térmicas. A modelagem dos dados foi feita de acordo com o modelo Laslett Durango (Laslett et al., 1987). Essas simulações comparam parâmetros estimados de idade e distribuição dos comprimentos de traços confinados de uma provável história térmica pré-estabelecida com os valores determinados e medidos pelo analista. Os resultados desse processo são curvas que representam o melhor ajuste para as histórias térmicas das amostras estudadas e uma estimativa do início do registro da passagem das amostras na base da zona de estabilidade parcial dos traços de fissão. A escolha do modelo de Laslett Durango foi feita por serem as amostras fluorapatitas. Adicionalmente, para a amostra sedimentar foi empregado o método proposto por Sambrigde \& Compston (1994) para discriminar as diferentes populações de idades.

\section{Resultados}

Os dados relativos à localização e altitude das amostras bem como os resultados analíticos traços de fissão são apresentados na tabela 2 . 0 conjunto datado tem mais de 30 grãos por amostra (exceto a amostra IT-23), no entanto, o número de traços confinados é reduzido (entre 6 e 20). 0 pequeno número de traços confinados medidos gera uma limitação na modelagem dos dados TFA. Portanto, as idades modeladas para os episódios de resfriamento e aquecimento aqui identificados não devem ser tomadas como idades exatas, mas indicativas de tendências para intervalos de idades.

\subsection{Amostras situadas a leste do rio Tapajós}

A amostra IT-18, coletada na rodovia BR-163, foi a que apresentou a idade aparente TFA mais antiga (258 Ma) (Fig. 1B e tab. 2). Esta amostra é utilizada como referência para a discussão da modelagem térmica das amostras coletadas a leste do rio Tapajós (BR-163), em função de apresentar uma das maiores concentra- 
ções de traços confinados (Fig. 2). A modelagem dessa amostra sugere que a sua história térmica iniciou com um lento resfriamento $\left(0,10^{\circ} \mathrm{C} / \mathrm{Ma}\right)$ em $306 \mathrm{Ma}$ e que perdurou até $176 \mathrm{Ma}$ (Fig. 3A, tab. 3). Posteriormente, ela foi submetida a um lento episódio de aquecimento até $98 \mathrm{Ma}$, mas permaneceu no topo da Zona de Apagamento Parcial (ZAP) ao longo de todo esse período de tempo, com temperaturas entre 73 e $60^{\circ} \mathrm{C}$. Após $98 \mathrm{Ma}$ ela iniciou o resfriamento final atingindo a estabilidade total dos traços.

A amostra IT-12 foi coletada a NE da amostra IT-18 e as demais a SW (Fig. 1B). A amostra IT-14, com uma idade aparente TFA de 194,9 Ma (Fig. 1B, tab. 2) iniciou a sua história térmica há 286 Ma com um resfriamento lento (TAR $=0,14{ }^{\circ} \mathrm{C} / \mathrm{Ma}$ ), seguido por um episódio de aquecimento há 201 Ma (Tab. 3). Posteriormente, há
$110 \mathrm{Ma}$, iniciou o segundo período de resfriamento.

A idade aparente TFA da amostra IT-15 é de 219,6 Ma (Fig. 1B, tab. 2). A sua história termal começou há $\sim 290$ Ma com resfriamento que durou até $226 \mathrm{Ma}$, em um processo relativamente acelerado $\left(\mathrm{TAR}=0,75^{\circ} \mathrm{C} /\right.$ Ma). Nesta ocasião, a amostra atingiu a temperatura superior da Zona de Apagamento Parcial (ZAP) dos traços de fissão. Em seguida, iniciou um processo de aquecimento que se prolongou até $111 \mathrm{Ma}$, quando então, teve início o segundo episódio de resfriamento (Tab. 3). De um modo geral, as amostras IT-14 e IT-15 tem um comportamento similar àquele da amostra IT18 , no sentido de que ambas apresentam um primeiro episódio de resfriamento próximo de 300 Ma e um segundo episódio de resfriamento, sucedendo ao evento de aquecimento, iniciado na faixa de $110-100 \mathrm{Ma}$.

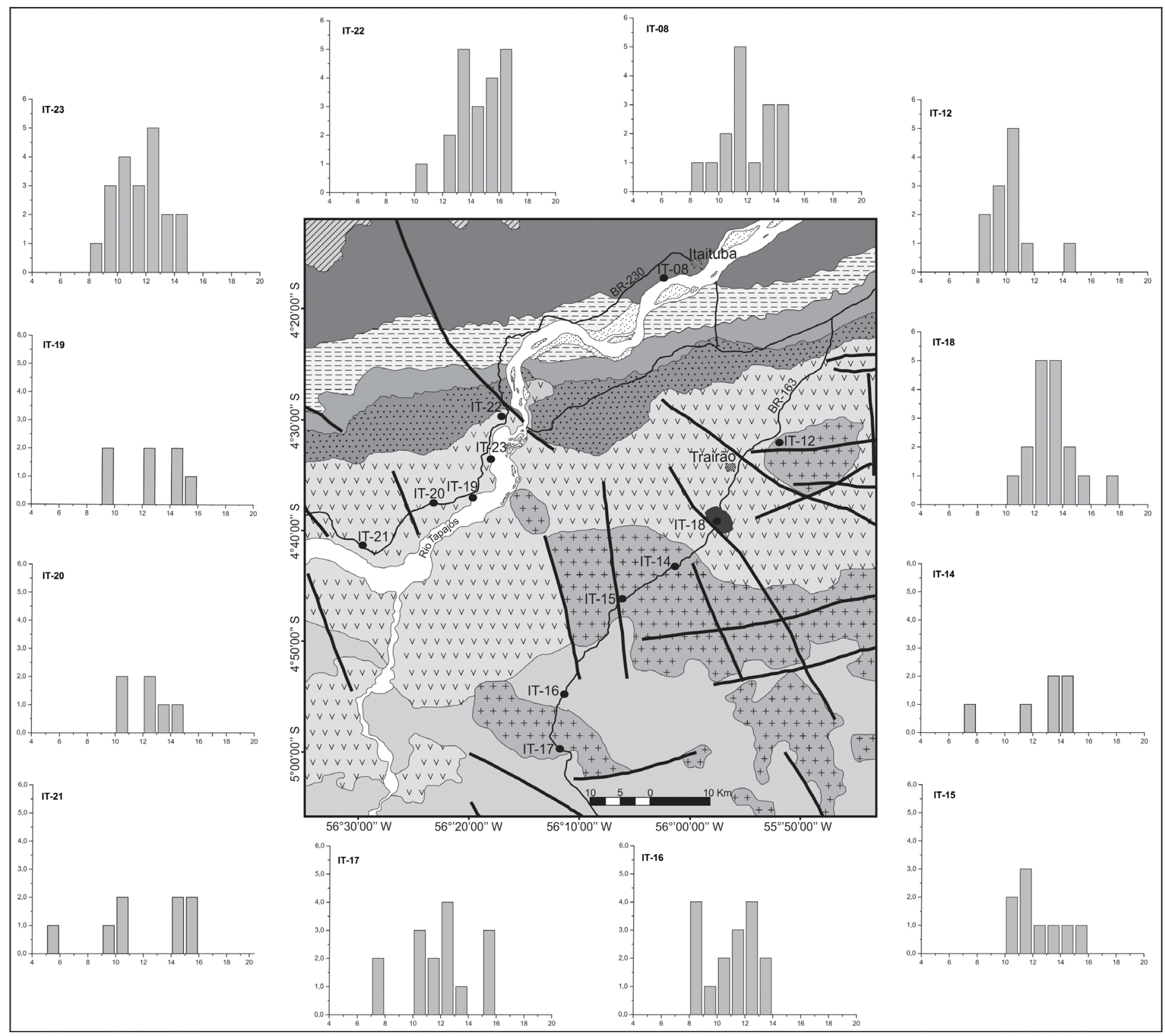

Figura 2. Mapa geológico da área de estudo com a localização dos pontos datados e os diagramas de distribuição dos comprimentos dos traços confinados para cada amostra, com número de traços confinados no eixo X e comprimento dos traços confinados ( $\mu$ m) no eixo Y. 
A amostra IT-16 apresenta a idade aparente TFA mais jovem, de 163 Ma (Fig. 1B, Tab. 2). Sua modelagem indica que o resfriamento iniciou há $392 \mathrm{Ma}$, com uma TAR de $0,12^{\circ} \mathrm{C} / \mathrm{Ma}$, e durou até $154 \mathrm{Ma}$ (Tab. 3). Em seguida, ocorreu um episódio de aquecimento até atingir a idade de 62 Ma quando então, teve início o segundo episódio de resfriamento, mais acelerado (TAR $=1,07$ ${ }^{\circ} \mathrm{C} / \mathrm{Ma}$ ), até alcançar a zona de estabilidade dos traços de fissão. A amostra IT-17 tem uma idade aparente TFA de 190,3 Ma (Fig. 1B, tab. 2), com início do episódio de resfriamento ocorrendo há 294 Ma e se prolongando até $181 \mathrm{Ma}$, quando começou o processo de aquecimento sucedido, há $117 \mathrm{Ma}$, pelo segundo episódio de resfriamento (Tab. 3). Embora essa amostra esteja mais afastada das amostras IT-14, IT-15 e IT-18 do que a amostra IT-16 (Fig. 1B), ela apresenta um com- portamento similar ao daquele conjunto de amostras, pois registra os sucessivos episódios de resfriamento e aquecimento, aproximadamente, na mesma faixa de idade (Tab. 3).

A idade aparente da amostra IT-12 é de 181,6 Ma (Fig. 1B, Tab. 2). A sua história termal teve início com um episódio de aquecimento há $282 \mathrm{Ma}$, ou seja, na mesma faixa de idade da maioria das amostras coletadas a leste do rio Tapajós. Entretanto, este episódio ocorreu por um período de tempo mais curto $(\sim 24$ $\mathrm{Ma}$ ), encerrando há $258 \mathrm{Ma}$, quando então é sucedido por um episódio de aquecimento que se prolonga por mais de $150 \mathrm{Ma}$ (Tab. 3). 0 segundo episódio de resfriamento teve início há $103 \mathrm{Ma}$, portanto na mesma faixa de idade do resfriamento observado na grande maioria das amostras coletadas ao longo da rodovia BR-163.
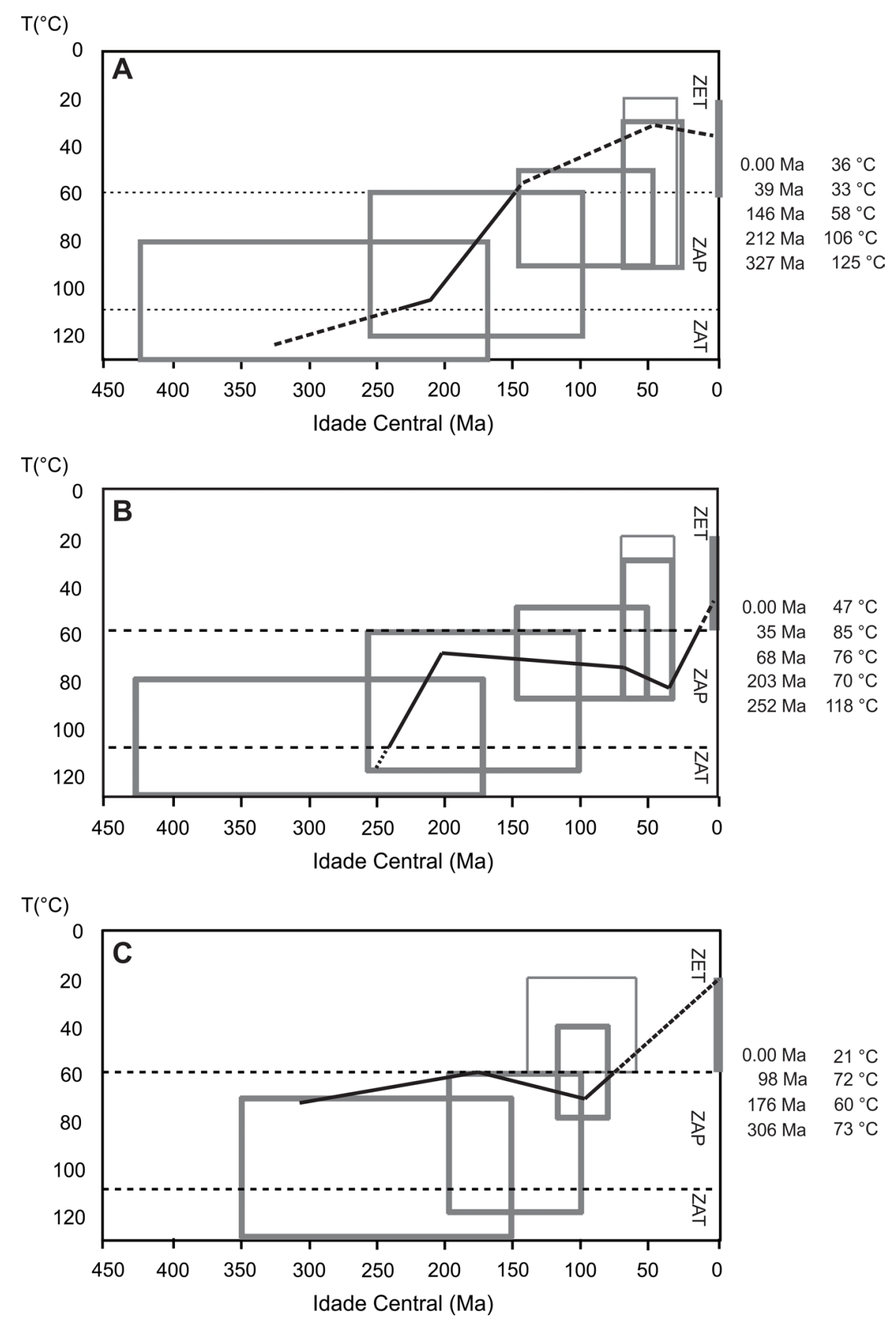

Figura 3. Representação gráfica da modelagem térmica obtida para as amostras: A) IT-18, B) IT-22 e C) IT-23, ZET: zona de estabilidade total, ZAP: zona de apagamento parcial, ZAT: zona de apagamento total. 
Tabela 3. Estimativa das taxas aparentes de resfriamento e aquecimento, interpretadas como taxas de soerguimento e subsidência, obtidas a partir da modelagem de dados traços de fissão das amostras de Itaituba, Pará.

\begin{tabular}{|c|c|c|c|c|c|c|c|c|c|c|}
\hline \multirow[b]{2}{*}{ Localização } & \multirow[b]{2}{*}{ Amostras } & \multicolumn{3}{|c|}{$1^{\circ}$ Episódio Soerguimento } & \multicolumn{3}{|c|}{ Evento Subsidência/Soerguimento } & \multicolumn{3}{|c|}{$2^{\circ}$ Episódio Soerguimento } \\
\hline & & $\begin{array}{c}\text { Idade } \\
\text { modelada } \\
\text { (Ma) }\end{array}$ & $\begin{array}{c}\text { Temperatura } \\
\text { inicial } \\
\left({ }^{\circ} \mathrm{C}\right)\end{array}$ & $\begin{array}{c}\text { TAR } \\
\left({ }^{\circ} \mathrm{C} / \mathrm{Ma}\right)\end{array}$ & $\begin{array}{l}\text { Idade } \\
\text { modelada } \\
(\mathrm{Ma})\end{array}$ & $\begin{array}{c}\text { Temperatura } \\
\text { inicial } \\
\left({ }^{\circ} \mathrm{C}\right)\end{array}$ & $\begin{array}{c}\text { TAA/ } \\
\text { TAR } \\
\left({ }^{\circ} \mathrm{C} / \mathrm{Ma}\right)\end{array}$ & $\begin{array}{c}\text { Idade } \\
\text { modelada } \\
\text { (Ma) }\end{array}$ & $\begin{array}{c}\text { Temperatura } \\
\text { inicial } \\
\left({ }^{\circ} \mathrm{C}\right)\end{array}$ & $\begin{array}{c}\text { TAR } \\
\left({ }^{\circ} \mathrm{C} / \mathrm{Ma}\right)\end{array}$ \\
\hline \multirow{6}{*}{ 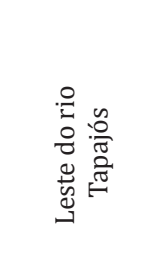 } & IT-12 & 282 & 97 & 0,95 & 258 & 74 & 0,09 & 103 & 88 & 0,65 \\
\hline & IT-14 & 286 & 91 & 0,14 & 201 & 79 & 0,11 & 110 & 89 & 0,73 \\
\hline & IT-15 & 290 & 110 & 0,75 & 226 & 62 & 0,16 & 111 & 80 & 0,33 \\
\hline & IT-16 & 392 & 108 & 0,12 & 154 & 79 & 0,11 & 62 & 89 & 0,78 \\
\hline & IT-17 & 294 & 95 & 0,12 & 181 & 81 & 0,13 & 117 & 89 & 0,51 \\
\hline & IT-18 & 306 & 73 & 0,10 & 176 & 60 & 0,15 & 98 & 72 & 0,43 \\
\hline \multirow{4}{*}{ 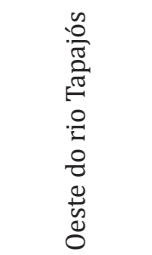 } & IT-08 & 162 & - & - & 106 & 97 & 0,25 & 58 & 85 & 0,66 \\
\hline & $\begin{array}{c}\text { IT- } 19,20 \\
21\end{array}$ & 280 & 110 & 0,20 & 148 & 84 & 0,12 & 96 & 90 & 0,68 \\
\hline & IT-22 & 226 & 110 & 0,29 & 212 & 106 & 0,72 & 146 & - & - \\
\hline & IT-23 & 240 & 110 & 1,08 & 203 & 70 & 0,09 & 35 & 85 & 1,09 \\
\hline
\end{tabular}

TAR: Taxa aparente de resfriamento; TAA: Taxa aparente de aquecimento; Idade modelada TF e Temperatura inicial são aquelas determinada por modelagem a partir do programa MonteTrax.

\subsection{Amostras situadas a oeste do rio Tapajós}

As amostras IT-22 e IT-23, coletadas próximas à rodovia BR-230, a oeste do rio Tapajós, estão distantes entre si aproximadamente $6 \mathrm{Km}$. Elas apresentam idades TFA aparentes de 177,5 Ma e 170,1 Ma, respectivamente (Fig. 1B e tab. 2) e são utilizadas como referência para a discussão da modelagem térmica das amostras do embasamento coletadas a oeste do rio Tapajós (Fig. 2). A modelagem dos traços confinados da amostra IT22 indicou um continuo resfriamento a partir de $\sim 226$ $\mathrm{Ma}$, com uma taxa aparente de resfriamento (TAR) de $0,29^{\circ} \mathrm{C} / \mathrm{Ma}$. Há $212 \mathrm{Ma}$ esta taxa se acelera atingindo um valor de $0,72{ }^{\circ} \mathrm{C} / \mathrm{Ma}$, até a saída da ZAP e estabilização total dos traços (Fig. 3B, tab. 3). A amostra IT-23 apresenta um resfriamento a partir de $\sim 240 \mathrm{Ma}$, com uma TAR de $1,09^{\circ} \mathrm{C} / \mathrm{Ma}$. No entanto, contrariamente da amostra IT-22 que foi submetida a um resfriamento contínuo, ela iniciou um episódio de aquecimento a partir de 203 Ma que seguiu até $35 \mathrm{Ma}$. Em seguida, ela foi submetida a um segundo episódio de resfriamento mais rápido $\left(1{ }^{\circ} \mathrm{C} / \mathrm{Ma}\right)$, sendo alçada para níveis crustais mais superficiais (Fig. 3C, tab. 3).

As amostras IT-19, IT-20 e IT-21, também coletadas ao longo da rodovia BR-230, apresentam idades aparentes TFA de 147,4 Ma, 146,4 Ma e 142,4 Ma, respectivamente (Tab. 2 e fig. 1B). Como essas amostras possuem idades aparentes muito próximas e desvio padrão da ordem de $10 \%$, elas foram modeladas conjuntamente já que apresentaram poucos traços confinados.
Assim, a história térmica desse conjunto de amostras iniciou-se há $\sim 280 \mathrm{Ma}$ com uma taxa de resfriamento lenta e regular $\left(0,20^{\circ} \mathrm{C} / \mathrm{Ma}\right)$ até $148 \mathrm{Ma}$, quando então passaram por um processo de aquecimento até $96 \mathrm{Ma}$ (Tab. 3). Desde então, esse conjunto de amostras passou a ter um resfriamento acelerado com uma TAR de $1,0^{\circ} \mathrm{C} /$ Ma até sair da ZAP.

A amostra IT-8, arenito da Formação Monte Alegre, foi coletada na margem esquerda do rio Tapajós. A deposição dessa amostra, cuja idade foi determinada a partir da análise de palinomorfos (Playford \& Dino, 2000) é westphaliana $A B$, ou seja dentro do intervalo 318-316 Ma, bastante distinta da idade aparente TFA de 91 Ma mostrando que esta não tem significado geológico direto. Como se trata de uma amostra de rocha sedimentar onde os grãos individuais podem ter populações de idades diferentes foi aplicado dois tratamentos estatísticos distintos na tentativa de interpretação dos dados TFA.

Na primeira abordagem foi possível discriminar duas populações com idades de 64 e 105 Ma, sendo a população de idade Paleógena definida com $88 \%$ dos grãos (Fig. 4A). Por sua vez, a modelagem por MonteTrax sugere que há 162 Ma a amostra estava situada na base da ZAP com uma temperatura de $96^{\circ} \mathrm{C}$. Em seguida ela foi submetida a um episódio de resfriamento que teve início há $106 \mathrm{Ma}$. Esse resfriamento inicial foi lento $\left(0,25^{\circ} \mathrm{C} / \mathrm{Ma}\right)$ e foi sucedido por outro mais acelerado $\left(0,64^{\circ} \mathrm{C} \mathrm{Km}\right)$ iniciado há $58 \mathrm{Ma}$ (Fig. 4B). 

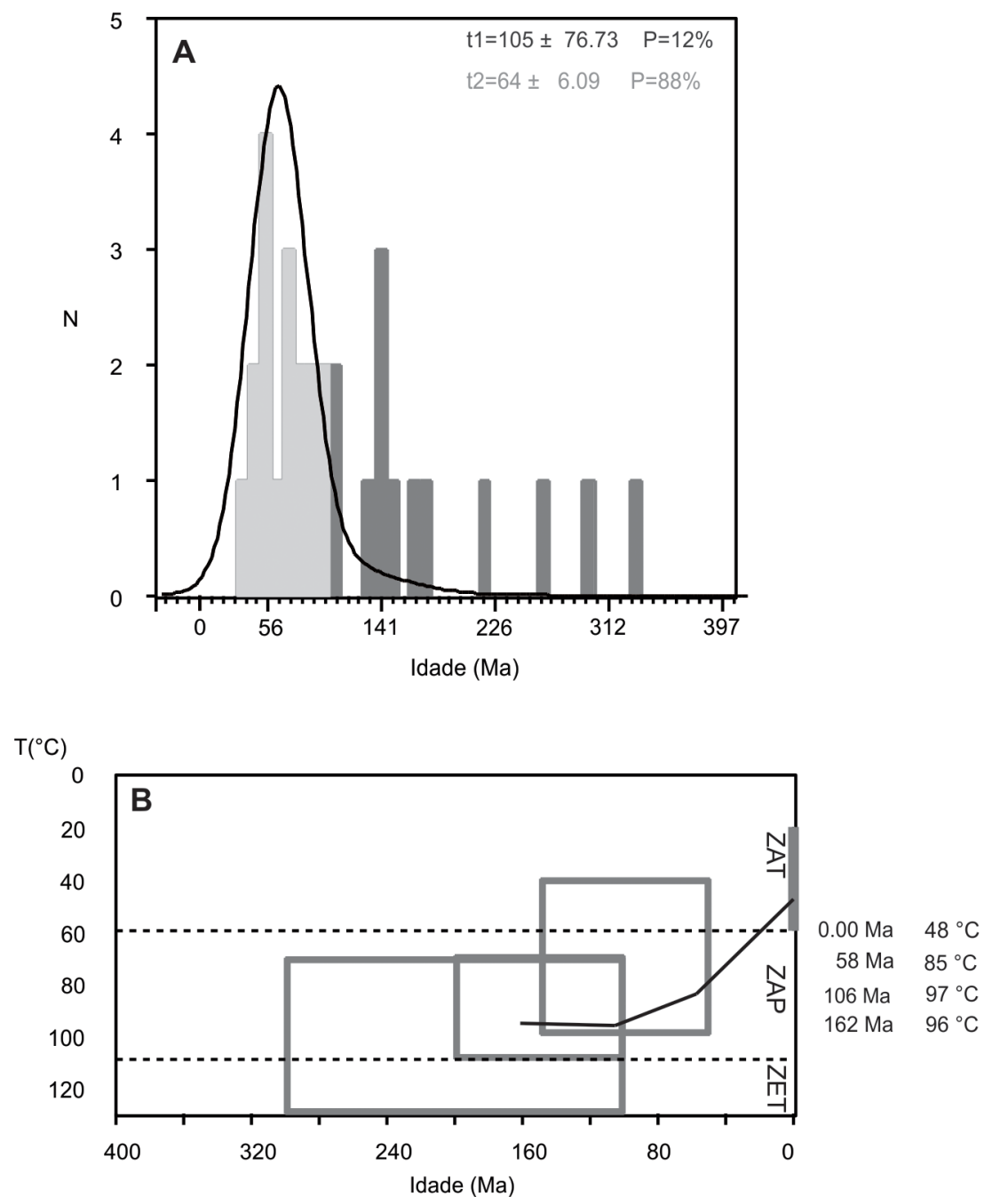

Figura 4. A) Histograma das idades TFA mostrando dois picos principais há 64 Ma e há 105 Ma com probabilidades de $88 \%$ e $12 \%$ respectivamente. 0 diagrama tem como abscissa as idades aparentes TFA e como ordenada o número de grãos detríticos. B) Representação gráfica da modelagem térmica obtida para a amostra IT-08. ZET (zona de estabilidade total), ZAP (zona de apagamento parcial), ZAT (zona de apagamento total).

\section{Discussão}

As idades aparentes TFA das amostras datadas do embasamento variam no intervalo entre 163 e $258 \mathrm{Ma}$ que, a princípio, não guarda uma relação com os eventos geológicos reconhecidos na região, nem mostra uma tendência clara que possa ser diretamente relacionada com a evolução geológica da área. No entanto, a modelagem permitiu identificar histórias térmicas específicas das amostras que podem auxiliar na interpretação das idades aparentes TFA. 0 fato da amostra IT-18 ter permanecido em níveis crustais mais superficiais durante um longo período de tempo, e em baixas temperaturas, pode explicar a sua idade aparente mais antiga (258 Ma) e a presença de traços confinados médios $(\mathrm{Lc}=12,8 \mu \mathrm{m})$ (Tab. 2 e fig. 2). Por outro lado, a idade mais jovem da amostra IT-16 pode estar relacionada ao fato de ter permanecido por um longo período de tempo ( 200 Ma) na porção mais basal da ZAP, e próximo da temperatura limite de apagamento dos traços o que certamente favoreceu o apagamento parcial dos traços resultando em uma idade TFA mais jovem
(163 Ma), e formação de traços significativamente mais curtos ( $\mathrm{Lc}=10,5 \mu \mathrm{m})$ (Fig. 2).

A idade aparente de 219,6 Ma da amostra IT-15 é mais antiga que aquela da amostra IT-14 (194,9 Ma). Isso pode estar relacionado ao fato da amostra IT-15 ter sido alçada às porções mais superficiais da ZAP e, durante o episódio de aquecimento, essa amostra não ultrapassou temperaturas superiores a $80^{\circ} \mathrm{C}$. Por sua vez, a amostra IT-14 durante o primeiro episódio de resfriamento, atingiu temperaturas próximas de $80^{\circ} \mathrm{C}$ para em seguida sofrer um novo episódio de re-aquecimento até atingir uma temperatura de $89^{\circ} \mathrm{C}$. Dessa forma, a amostra IT-14 permaneceu em uma região mais quente da ZAP o que certamente favoreceu o apagamento parcial dos traços resultando em uma idade mais jovem.

Duas particularidades chamam atenção na amostra IT-12. A primeira é a idade média aparente $(181,6$ $\mathrm{Ma}$ ) mais jovem que aquelas do conjunto de amostras mais próximas (IT-18 = 259 Ma; IT-14 = 195 Ma; IT-15 $=220 \mathrm{Ma}$ ). Tal diferença pode ser explicada pelo longo período de aquecimento dessa amostra ( $150 \mathrm{Ma}$, tab. 
3) que favoreceu o apagamento parcial dos traços de fissão e gerou traços mais curtos ( $\mathrm{Lc}=9,87 \mu \mathrm{m}$ ) (Fig. 2). A outra observação importante é o fato da amostra IT-12 estar separada das demais por uma falha de direção NW-SE, cuja extensão pode ser inferida por dezenas de quilômetros (Fig. 1B). Essa descontinuidade entre estes dois compartimentos pode ter gerado um movimento diferencial entre os blocos resultando no aquecimento mais precoce do bloco setentrional, como sugerido pela modelagem.

Aliás, a análise das idades TFA das amostras situadas a leste do rio Tapajós, mostra uma alternância entre idades mais jovens e mais velhas. Observam-se ainda no mapa geológico diversas falhas, com direção variando entre NW-SE e NNW-SSE, definindo diferentes compartimentos e, em geral, as amostras coletadas situam-se em compartimentos distintos (Fig. 1B). Assim, é possível que esta alternância das idades esteja refletindo o movimento relativo, que resultou na presença de blocos abatidos e blocos elevados. Neste caso, nos blocos abatidos as idades TFA seriam mais jovens que nos blocos elevados, pois estes últimos teriam permanecido nas zonas mais superficiais da ZAP. Todavia, a escala do mapa geológico e a falta de informação sobre o tipo de movimento e rejeito das falhas são limitações para essa inferência.

Em geral, as idades aparentes TFA das amostras do embasamento situadas a oeste do rio Tapajós são mais jovens do que aquelas das amostras localizadas a leste do rio (Fig. 1B). Provavelmente, essa diferença de idades está relacionada ao fato desses dois conjuntos de amostras estarem situados em segmentos crustais separados por falhas, cujas presenças são evidenciadas pela forte linearidade do rio Tapajós nesta área (NE-SW, N-S e NW-SE), e pelo intenso fraturamento observado em campo no local de coleta da amostra IT- 23.

Com a exceção da amostra IT-22 cuja modelagem indica um contínuo resfriamento, para as demais amostras localizadas a oeste do rio Tapajós, a modelagem mostra um primeiro episódio de resfriamento seguido de um aquecimento e um segundo (e final) episódio de resfriamento. No entanto, a modelagem sugere uma defasagem temporal desses eventos entre a amostra IT23 e o conjunto de amostras IT-19, IT-20 e IT-21. Nestas últimas, o resfriamento iniciou há $280 \mathrm{Ma}$ e o aquecimento há $148 \mathrm{Ma}$, enquanto na amostra IT-23 o resfriamento iniciou há $240 \mathrm{Ma}$ e o aquecimento há $203 \mathrm{Ma}$, indicando um período de tempo mais curto de resfriamento e mais longo de aquecimento para essa amostra. Adicionalmente, a etapa final de resfriamento também é distinta uma vez que na amostra IT-23 ele ocorre há $35 \mathrm{Ma}$ e no conjunto de amostras IT-19, IT-20 e IT-21 ele ocorreu há 100 Ma. Outra observação que merece registro é o fato do primeiro episódio de resfriamento apresentar um aumento progressivo na idade no sentido sudoeste, iniciando em $\sim 226$ Ma (amostra IT-22) e atinge $\sim 280$ Ma (amostras IT-19, IT-20 e IT-21). Isso contrasta com as idades TFA que diminuem no sentido

\section{NE-SW (Fig 1B).}

Em geral, a modelagem das amostras estudadas registrou dois episódios de resfriamento separados por uma etapa de aquecimento. Apenas as amostras IT-22 e IT-08 (rocha sedimentar) não mostram a etapa de aquecimento. As idades obtidas para o primeiro episódio de resfriamento, para a maioria das amostras, situou-se entre $280 \mathrm{Ma}$ e $306 \mathrm{Ma}$. Este intervalo de idade coincide, aproximadamente, com aquele de dois eventos geológicos reconhecidos mundialmente, e que podem resultar no soerguimento crustal. 0 primeiro é a aglutinação do Pangéia que ocorreu na faixa de 320 a $270 \mathrm{Ma}$ (Ford \& Golonka, 2003; Veevers, 2004). 0 segundo foi a deglaciação do Gondwana no final do Carbonífero e início do Permiano (Wopfner, 1999).

Um segundo episódio de resfriamento com início na faixa de 117-98 Ma foi registrado pela maioria das amostras do embasamento, e é associado ao soerguimento e exumação da crosta. Esta exumação pode ter sido causada pela deformação das rochas da porção sudoeste da Bacia do Amazonas no Eocretáceo, que originou a formação de anticlinais assimétricas e falhas reversas NE-SW nas unidades pré-cretácicas na região do Tapajós (Campos \& Teixeira, 1988). Essa inversão positiva nas rochas da bacia foi relacionada a esforços compressionais causados pelo processo de abertura do Atlântico Equatorial a leste e a zona de subducção andina cretácica a oeste da placa Sul-americana (Campos \& Teixeira, 1988). Este episódio tem sido associado ao Diastrofismo Juruá, e interpretado como a mais expressiva deformação que afetou a Plataforma Sul-Americana durante a reativação Wealdeniana (Zalán, 2004). A amostra IT-22 não registrou este evento, pois nesta ocasião encontrava-se na zona de estabilidade total dos traços. Por sua vez, a modelagem das amostras IT-16 e IT-23 sugere que elas se encontravam em processo de aquecimento durante este período devido, possivelmente, a elas se situarem em compartimentos que estavam sofrendo abatimento durante esta deformação.

0 episódio de aquecimento situado entre os dois eventos de soerguimento observados nas rochas do embasamento da Bacia do Amazonas não foi bem delimitado temporalmente na modelagem de traços de fissão. 0 intervalo de idades varia entre 258 e 148 $\mathrm{Ma}$, embora cinco amostras apresentem um intervalo mais restrito (203 - $176 \mathrm{Ma}$ ). Este intervalo restrito de idade, de certa forma, pode estar correlacionado ao Magmatismo Penatecaua ( 200 Ma), amplamente registrado na Bacia do Amazonas e associado à ruptura do Pangéia e formação do Atlântico Central (Deckart et al., 2005). Este evento magmático de escala continental causou o aquecimento generalizado das rochas do embasamento da bacia e certamente favoreceu o apagamento parcial dos traços de fissão. No entanto, as rochas do embasamento aqui estudadas estão situadas em compartimentos distintos separados por falhas que causaram movimentação diferencial dos mesmos. Em função disso, essas rochas poderiam estar em diferen- 
tes profundidades na ZAP na época do magmatismo. Isso causaria uma diferença no registro das idades que apresentariam uma maior dispersão para este período de aquecimento. Assim, este intervalo de tempo obtido por meio da modelagem, pode ser a expressão de um evento de aquecimento crustal, associado ao magmatismo máfico, e que afetou de modo diferencial as rochas em função de seu posicionamento (profundidade) nos diferentes compartimentos do terreno.

A alternativa de se associar este episódio de aquecimento a um evento de subsidência regional não parece ser adequada em função da falta de registro de sedimentação na Bacia do Amazonas entre o Triássico e o Cretáceo Inferior. No entanto, o intenso falhamento das rochas do embasamento pode ter causado localmente, a subsidência de alguns blocos uma vez que a modelagem das amostras IT-16 e IT-23 sugerem um mais longo período de aquecimento.

Finalmente, os diferentes tratamentos estatísticos aplicados aos dados TFA da amostra de arenito (IT-08) sugerem que o segundo episódio de soerguimento observado nas rochas do embasamento (117 - $98 \mathrm{Ma}$ ) foi registrado em rochas da Bacia do Amazonas. No entanto, além desse episódio de exumação identificado há $106 \mathrm{Ma}$, a modelagem dessa rocha sedimentar indicou a existência de um segundo evento de resfriamento há 58 Ma que marca um período de aceleração no processo de exumação. 0 registro deste evento do Paleógeno está preservado apenas em uma amostra do embasamento (IT-16).

\section{Conclusões}

As rochas do embasamento da Bacia do Amazonas forneceram idades TFA entre 163 e $258 \mathrm{Ma}$. As amostras situadas na porção oeste do rio Tapajós apresentam idades TFA mais jovens que aquelas situadas na porção leste. Essa diferença de idades sugere que as amostras do lado leste desse rio encontravam-se a altitudes mais elevadas que aquelas do lado oeste. A existência de falhas evidenciadas pela linearidade do rio Tapajós fortalece a hipótese de que estes dois conjuntos de amostras podem estar situados em segmentos crustais distintos separados por falhamentos. Da mesma forma, o intenso falhamento de direção NW-SE é considerado o responsável pela alternância de idades mais jovens e mais antigas observadas nas rochas situadas na porção leste do rio Tapajós. Nesse caso, devido ao abatimento e soerguimento de blocos as rochas se situaram em diferentes profundidades ao longo da história de exumação da área.

Dois eventos de resfriamento (soerguimento) intercalados a um evento de aquecimento foram identificados na modelagem dos dados de traços de fissão. 0 primeiro episódio de resfriamento (280-306 Ma) pode estar relacionado à aglutinação do Pangéia (320$270 \mathrm{Ma})$ e a deglaciação do Gondwana ( $300 \mathrm{Ma})$. 0 episódio final de resfriamento (117-98 Ma) pode estar relacionado à deformação que ocorreu nas rochas da porção sudoeste da Bacia do Amazonas durante o Eocretáceo. A etapa intermediária de aquecimento pode estar relacionada ao magmatismo Penatecaua $(\sim 200$ $\mathrm{Ma}$ ) registrado na Bacia do Amazonas, e associado à ruptura do Pangéia e formação do Atlântico Central.

Uma única amostra sedimentar foi datada método dos traços de fissão em apatita na bacia. Trata-se da amostra de arenito da Formação Monte Alegre e que apresentou uma idade TFA de $91 \mathrm{Ma}$. Essa amostra registrou dois eventos de soerguimento, um primeiro há 106 Ma coincidente com o evento de soerguimento registrado pelas rochas do embasamento, e outro evento registrado há 58 Ma que sugere a presença da tectônica cenozóica afetando as rochas da Bacia do Amazonas, que foi registrada em algumas amostras do embasamento.

Agradecimentos: Este trabalho foi desenvolvido como parte da dissertação de mestrado de Aline Pina no Programa de Pós-Graduação em Geologia e Geoquímica da UFPA, com bolsa de estudo concedida pelo CNPq. O trabalho contou com o apoio do auxílio integrado de pesquisa do $\mathrm{CNPq}$ 550710/2005-1, e da infra-estrutura dos laboratórios de geologia isotópica do IG-UFPA e da IGEO-UFRGS.

\section{Referências}

Almeida, F.F.M. 1972. Tectono-magmatic activation of the South American Platform and associated mineralization. In: INTERNATIONAL GEOLOGICAL CONGRESS, 24. Montreal, Proceedings... IUGS. Section 3, Tectonics, 339-346.

Campos, J.N.P. \& Teixeira L.B. 1988. Estilos tectônicos da Bacia do Amazonas. In: CONGRESSO BRASILEIRO DE GEOLOGIA, 35. 1988. Belém. Anais..., Belém, SBG, v. 5, p. 21612172.

Caputo M.V., Rodrigues R. \& Vasconcelos D.N.N. 1971. Litoestratigrafia da Bacia do Amazonas. RENOR-Petrobras, 92 p. (relatório Interno).

CPRM. COMPANHIA DE PESQUISA DE RECURSOS MINERAIS. 2009. Mapa Geológico do Estado do Pará. Belém-Pará, CPRM. GIS-BRASIL, escala: 1/500.000.

Cunha, F.M.B., Gonzaga F.G., Coutinho L.F.C. \& Feijó F.J. 1994. Bacia do Amazonas. Boletim de Geociências da Petrobras, 8(1): 47-55.

Cunha, P.R.C., Melo, J.H.G. \& Silva, O.B. 2007. Bacia do Amazonas. Boletim de Geociências da Petrobras, 15(2): 227-251.

Deckart, K.T., Bertrandb, H. \& Liégeois, J.P. 2005. Geochemistry and $\mathrm{Sr}, \mathrm{Nd}, \mathrm{Pb}$ isotopic composition of the Central Atlantic Magmatic Province (CAMP) in Guyana and Guinea. Lithos, 82: 289-314.

Dunkl, I. 2002. A Windows program for calculation and graphical presentation of fission track data. Computers and Geociences, 28(1): 3-12.

Eiras, J.F., Becker C.R., Souza E.M., Gonzada F.G., Silva J.V.F., Daniel L.M.F., Matsuda N.S. \& Feijó F.J. 1994. Bacia do Solimões. Boletim de Geociências da Petrobras, 8(1):17-45.

Ford, D. \& Golonka, J. 2003. Phanerozoic paleogeography, paleoenvironment and lithofacies maps of the circum-Atlantic margins. Marine and Petroleum Geology, 20: 249-285.

Galbraith R.F. \& Laslett G.M. 1993. Statistical models for mixed fission-track ages. Nuclear Tracks and Radiation 
Measurements, 21:459-470.

Gallagher, K., Sambridge M. \& Drijkoningen G. 1991. Genetic Algorithms: an evolution from Monte Carlo Methods for stronglynon-linear geophysical optimization problems. Geophysical Research Letters,18(12): 2177-2180.

Green, P.F., Duddy, I.R., Gleadow, A.J.W., Tingate, P.R. \& Laslett, G.M. 1986. Thermal Annealing of Fission Tracks in Apatite - A Qualitative Description. Chemical Geology (Isotope Geoscience Section), 59: 237-253.

Hurford, A.J. \& Green, P.F. 1983. The Zeta Age Calibration of fission Track Dating. Chemical Geology, Isotopic Geoscience, 1: 285-317.

Kohn, B.P. \& Green, P.F. 2002 (edit.). Low Temperature Thermochronology: from Tectonics to Landscape Evolution. Tectonophysics, 349.

Moura C.A.V., Gorayeb P.S.P., Matsuda N.S. 1999. Geocronologia $\mathrm{Pb}-\mathrm{Pb}$ em zircão do riolito Vila Raiol, formação Iriri-sudoeste do Pará. In: SBG, SIMPÓSIO DE GEOLOGIA DA AMAZÔNIA, 6, Resumos expandidos, p. 475-477.

Negrão, S.C.B. 2011. Datação pelo método de traços de fissão em apatita da região da estrutura dômica de Monte Alegre, Bacia do Amazonas (PA). Pará, 107p. Dissertação de Mestrado, Programa de Pós-graduação em Geologia e Geoquímica, Instituto de Geociências, Universidade Federal do Pará.

Playford, G. \& Dino, R. 2000. Palynostratigraphy of upper Palaeozoic strata (Tapajós Group), Amazonas, Brazil: Part Two. Palaeontographica, Abteilung B, 255(4-6): 87-145.

Santos, J.O.S, Artmann, L. A., Gaudette H. E., Groves D. I., Mcnaughton J. N. \& Fletcher I. R. 2000. New understanding of the Amazon Craton provinces, based on field work and radiogenic isotope data. Gondwana Research, 3(4): 453488.

Manuscrito 494.

Editores: Edinei Koester.
Sambrigde, M.S. \& Compston, W. 1994. Mixture modelling of multi-component data sets with application to ion-probe zircon ages. Earth and Planetary Science Letters, 128: 373-390.

Tassinari C.C.G. \& Macambira M.J.B. 1999. Geochronological provinces of the Amazonian craton. Episodes, 22:174182.

Tassinari, C.C.G. \& Macambira, M.J.B. 2004. A evolução tectônica do Cráton Amazônico. In: Mantesso-Neto et al. (eds.), Geologia do Continente Sul-Americano: Evolução da Obra de Fernando Flávio Marques de Almeida. São Paulo: Ed. Becca, p. 471-485.

Vasquez, M.L., Ricci, P.S.F. \& Klein, E.L. 2002. Granitóides pós-colisionais da porção leste da Província Tapajós. Contribuições à Geologia da Amazônia. Sociedade Brasileira de Geologia, Belém, Brasil, 3: 67-83.

Vasquez M.L., Klein E.L., Quadros M.L.E.S., Bahia R.B.C., Santos A., Ricci P.S.F., Sachett C.R., Silva C.M.G. \& Macambira M.J.B. 1999. Magmatismo Uatumã na Província Tapajós Novos dados geocronológicos. In: SBG, SIMPÓSIO DE GEOLOGIA DA AMAZÔNIA. Resumos expandidos, p. 471-474. Veevers, J.J. 2004. Gondwana from 650-500 Ma assembly through 320 Ma merger in Pangea to 185-100 Ma breakup: Supercontinental tectonics via stratigraphy and radiometric dating. Earth Science Reviews, 68 (1), 1-132.

Wopfner, H. 1999. The Early Permian deglaciation event between East Africa andnorthwestern Australia. Journal of African Earth Sciences, 29 (1), 77-90.

Zalán, P. V. 2004. Evolução fanerozóica das bacias sedimentares brasileiras. In: Mantesso-Neto et al. (eds.), Geologia do Continente Sul-Americano: Evolução da Obra de Fernando Flávio Marques de Almeida. São Paulo: Ed. Becca, p. 595-612. 